\title{
The fertility assessment of normal cyclic Wistar rats following the administration of methanolic extract of Portulaca oleracea: an experimental study
}

\author{
Izuchukwu Azuka Okafor ${ }^{1,2^{*}}$ (D, Uchenna Somtochukwu Nnamah ${ }^{3}$ and Jude Nnaka ${ }^{1}$
}

\begin{abstract}
Background: Purslane is a widely distributed shrub used for the treatment of different ailments. The increasing reproductive complications associated with herbal treatments have led to the need to critically evaluate the safety and/or reproductive potentials of commonly used plant extracts. This study investigated the reproductive effect of methanolic extracts of Portulaca oleracea (MEPO) in adult female Wistar rats.

Results: Group $C$ showed a significant decrease both in relative ovarian weight $(p=0.000)$, and relative uterine weight ( $p=0.037$ ), when compared with the control. There were no significant ( $p>0.05)$ changes in the levels of follicle-stimulating hormone, luteinizing hormone, progesterone, and estradiol. When compared to the control, groups B and C showed abnormal estrous cycle and cycle arrest especially at the metestrus phase with mild congestion of a few blood vessels in the ovary and uterus.

Conclusions: MEPO may possess some anti-fertility effect, as it disrupts the estrous cycle of adult female Wistar rats; although it has no major effect on the reproductive hormones, uterus, and ovarian histology of adult female Wistar rats. However, high dose consumption should be taken with precaution.
\end{abstract}

Keywords: Portulaca oleracea, Anti-fertility, Wistar rat, Estrous cycle, Reproductive hormones, Uterus, Ovary

\section{Background}

Infertility is a disease of the reproductive system defined by the failure to achieve a clinical pregnancy after 12 months or more of regular unprotected sexual intercourse $[1,2]$. It is a global phenomenon affecting an average of $10-15 \%$ (estimates range from 48 million to 180 million) of reproductive-aged couples [3, 4]. It affects both men and women with almost equal frequency $[3,5]$. The cases of increased infertility issues among

\footnotetext{
* Correspondence: okaforizuchukwu33@gmail.com; iza.okafor@unizik.edu.ng ${ }^{1}$ Department of Anatomy, Faculty of Basic Medical Sciences, College of Health Sciences, Nnamdi Azikiwe University, Nnewi Campus, PMB 5001, Nnewi, Nigeria

2Department of Obstetrics and Gynaecology, College of Medicine, Pan African University of Life and Earth Science Institute (Including health and Agriculture) PAULESI, University of Ibadan, Ibadan, Nigeria Full list of author information is available at the end of the article
}

female humans seem to be on the rise; female infertility occurs in about $37 \%$ of all infertile couples and ovulatory disorders account for more than half of these [6]. The use of medicinal herbs and herbal medicines is an ageold tradition [7] and the recent progress in modern therapeutics has stimulated the use of natural products worldwide for diverse ailments and diseases [8]. Among the most common plants found in existence, the plant Portulaca oleracea (PO) is one that should attract attention. It belongs to the Portulacaceae family, a family of plants that are Fleshy and commonly used as herbs [9]. It is a naturally occurring plant found in various locations and is among the most common plants in the world [10]. Recent research demonstrates that Purslane has better nutritional quality than the major cultivated vegetables, with higher beta-carotene, ascorbic acid, and 
alpha-linolenic acid [11]. This plant has since been used as medicine by practitioners of alternative and traditional medicine, to act as a febrifuge, antiseptic, vermifuge, and so forth [12]. It is also used in the treatment of cardiovascular disorders, dysuria, haematuria, gonorrhea, dysentery, sore nipples, and ulcers of mouth [9]. In some places, this plant is consumed as food and is said to be nutritious because of its high omega- 3 fatty acid content and other minerals [13]. This plant has been studied and is listed by the World Health Organization as one of the most used medicinal plants, and has been given the name "Global Panacea" [14]. PO has been implicated in some reproductive effects, especially in male animals. Reproductive studies following the administration of purslane reported a reduction in sperm motility, decreased testosterone (TT) levels [15], and reduced sperm structure [16]. In some areas near Benin City (Nigeria), the plant, along with other ingredients, is taken as an aid to reproductive functions for males, and the development of the fetus in females [17]; a study also found PO to cause some alterations in the estrous cycle [10]. Following the known traditional and research-reported uses, the present study was undertaken to investigate the effects of methanolic extract of Portulaca oleracea (MEPO) on female fertility and offer scientific evidence to any claimed effect. It will further reduce the dearth of literature on the effect of PO on the female reproductive system and also evoke further research into the female reproductive potential of PO.

\section{Methods}

\section{Study setting}

This study was carried out in the research laboratory of the Department of Anatomy, Faculty of Basic Medical Sciences, Nnamdi Azikiwe University, College of Health Science, Nnewi Campus, Anambra State and lasted about 5 months as part of a thesis in the Department of Anatomy of Nnamdi Azikiwe University.

\section{Plant collection, identification, and extraction}

The aerial parts of the plant PO was obtained from marshy areas at Awka, Anambra State, Nigeria. The botanical identification (ID/155A/P. oleracea) and authentication were done in the herbarium of the Department of Botany, Edo State University, Ekpoma, Edo State. A large amount of the harvested plant was washed free of soil, and roots separated from the aerial part. It was airdried for 2 weeks then oven-dried at $40{ }^{\circ} \mathrm{C}$. The dried plant was ground giving a yield of about $500 \mathrm{~g}$. The sample was macerated and extracted with $70 \%$ methanol (1: $2 \mathrm{wt} / \mathrm{vol}$.) for $72 \mathrm{~h}$ at room temperature $\left(26-28{ }^{\circ} \mathrm{C}\right)$. The resulting solution was filtered, sieved, and $70 \%$ methanol was evaporated at a temperature of $40{ }^{\circ} \mathrm{C}$ to give a percentage yield of $10.2 \%$ of the starting material.

\section{Sample size determination}

The sample size was determined using the "resource equation" method for animal studies which is based on the degree of freedom of analysis of variance (ANOVA). However, this study considered an attrition rate of $10 \%$ for each group, thus giving a total sample size of fifteen (15) animals (five animals per group) $[18,19]$.

\section{Animal source, care, and handling}

The animals were procured from the animal house of the Faculty of basic medical sciences, College of Health Sciences, Nnamdi Azikiwe University, Nnewi Campus, Nnewi Nigeria. The Wistar rats were acclimatized for 2 weeks after which the animals were housed in standard cages, five per cage in a controlled temperature room $\left(25{ }^{\circ} \mathrm{C}\right)$, with a $12 \mathrm{~h}$ light: $12 \mathrm{~h}$ dark cycle; lights on at 6 : 00 a.m. Standard laboratory rat chow and tap water were made available throughout the study period. Fifteen (15) normal cyclic female Wistar rats weighing between 150 and $200 \mathrm{~g}$ were used for the experiment. The experimental procedures complied with ARRIVE guidelines [20] and the National Institutes of Health guide for the care and use of laboratory animals (2011). Animal health status was monitored throughout the experiment according to the federation of European Laboratory Animal Science Associations (FELASA) guidelines [21].

\section{Vaginal smear cytology and estrous cycle evaluation}

The estrous cycle of the animals was observed by vaginal smear cytology before grouping and was repeated at the end of MEPO administration as only the normal cyclic rats were included in this study. The vagina smear was carried out consistently in the morning between 20:00 and 21:00 $\mathrm{h}$ throughout the smear duration. Before vaginal smear, each animal is held in position by grasping each rat on the suspended tail while fixing the animal on a stable flat surface with a mild clampdown of the hind using the dorsum of the hand. Vaginal secretion was collected by inserting a plastic pipette filled with $10 \mu \mathrm{l}$ of normal saline $(\mathrm{NaCl} 0.9 \%)$ into the tip of the vagina for a suction aspiration of the cells and vaginal mucus. The secretion collected was then placed on the slide and viewed under a light microscope with $\times 10$ objective lenses. The proportion among the three types of cells (the round and nucleated ones-epithelial cells; the irregular anucleated ones-cornified cells; and the little round ones-leukocytes) were used for the determination of the estrous cycle phase of the animals. The smear cytology assessment was done by two individuals to avoid bias. Each animal was examined for two 4-day cycles to establish the regularity of the estrous cycle before inclusion in the study. In the end, 15 normal cyclic female Wistar rats were selected for this study. The cytology protocol followed in this study was as 
documented by Long and Evans [22], Mandl [23], and McLean et al. [24].

\section{Experimental procedure}

Female Wistar rats of proven fertility (normal cyclic) were divided into three (3) groups of five (5) animals each, based on their body weight. Group A served as the control group and they received only distilled water. Doses of $400 \mathrm{mg} \mathrm{kg}^{-1}$ day $^{-1}$ and $800 \mathrm{mg} \mathrm{kg}^{-1}$ day $^{-1}$ were administered to groups $B$ and $C$ orally for 14 days. One gram of the methanolic extract of $\mathrm{PO}$ was diluted with $20 \mathrm{ml}$ of distilled water to constitute the administration stock. The administration was based on the bodyweight of each rat in each group and remnant of the extract was discarded after each use. All administration was done orally using the oral cannula. The dosage, duration of administration, and experimental design were based on our previous study [17].

\section{Animal sacrifice and blood sample collection}

After the last day of administration (14th day), the animals were fasted overnight and sacrificed on the next day by cervical dislocation. Blood samples were collected by orbital puncture into sample collection tubes with the appropriate labels after which the animals were dissected and the ovary and uterine tissues were harvested and weighed. The average weight of the left and right ovaries and uterine horns were recorded for each animal and used to determine the organ weights.

\section{Hormonal analysis}

The collected blood was allowed to stand for $15 \mathrm{~min}$ in the specimen container under room temperature before centrifugation at $1000 \mathrm{~g}$ for $5 \mathrm{~min}$ in a refrigerated centrifuge and the serum was extracted. Analysis for follicle-stimulating hormone (FSH), luteinizing hormone $(\mathrm{LH})$, progesterone, and estradiol were carried out using AccuBind enzyme-linked immunosorbent assay (ELISA) microwells for FSH, LH, progesterone, and estradiol respectively purchased from Monobind Inc. Lake Forest CA USA with the respective product codes-4925-300, 4825-300, 425-300, and 625-300 respectively. AccuBind procedure was used for the assessment of FSH, LH, Estradiol, and progesterone [25]. The laboratory technician was unaware of the treatment allocation.

\section{Histopathological studies}

Ovarian and uterine tissues were fixed in Bouin's fluid immediately after excising them and were passed through ascending grades of alcohol before clearing in xylene and embedding in paraffin. Tissues were sectioned at $5 \mathrm{~m}$ and stained with hematoxylin and eosin to give contrasting colors to different elements of the cells or tissue thus making them conspicuous and easy to study. The tissues were viewed under the light microscope and the micrographs were taken using the digital micrography system. The histopathological assessment and procedure used in this study were based on the study by Rowley et al. [26].

\section{Data analysis}

The data analysis was done using the IBM statistical package for social science (SPSS) version 23.0. The data was cleaned and tested for normality using the Kolmogorov-Smirnov test. The animal body weights were analyzed using the dependent $t$ test while the relative organ weights and serum hormonal levels were analyzed using the one-way analysis of variance (ANOVA) and post-hoc LSD. Tables were used for result presentation, and values were considered significant at $p<0.05$. All the data generated for each animal were used for the analysis and each animal study group was considered as a single experimental unit.

\section{Results \\ Body weight measurement}

This study showed an insignificant $(p=0.155)$ increase in the body weight when the pre-administration weight was compared to the post-administration weight in group A. Group B had a significant $(p=0.002)$ increase when the pre-administration weight was compared to the post-administration weight. Group $\mathrm{C}$ had an insignificant $(p=0.302)$ increase when the preadministration weight was compared to the postadministration weight (Table 1).

\section{Relative organ weight measurements}

Results from the study showed a significant difference in relative ovarian weight in group $C(p=0.000)$ when compared to the control group. It also shows a significant decrease both in the left $\left(p=0.037^{*}\right)$ and right $(p=$ $\left.0.037^{*}\right)$ relative uterine weight in group $C$ when compared to the control group.

\section{Serum FSH, LH, progesterone, and estradiol level}

FSH result showed an insignificant $(p>0.05)$ increase in group $\mathrm{B}$, with an insignificant $(p>0.05)$ decrease in group $C$ when compared to group $A$. The result showed an insignificant $(p>0.05)$ decrease in serum LH levels in group B and $C$ when compared to group A. Progesterone result showed an insignificant $(p>0.05)$ increase in group B and C when compared to group A. Result obtained from estradiol analysis showed an insignificant $(p$ $>0.05$ ) decrease in group $\mathrm{B}$ and $\mathrm{C}$ when compared to group A estradiol level. 
Table 1 The effect of MEPO on the bodyweight of adult female Wistar rats

\begin{tabular}{llll}
\hline Groups & & Mean \pm SEM & $\boldsymbol{p}$ value \\
\hline A (control) & Pre-administration & $160.67 \pm 3.76$ & \\
& Post-administration & $179.67 \pm 10.20$ & 0.155 \\
B (400 mg/kg MEPO) & Pre-administration & $154.33 \pm 3.18$ & -1.747 \\
& Post-administration & $182.33 \pm 2.40$ & $0.002^{*}$ \\
C (800 mg/kg MEPO) & Pre-administration & $143.67 \pm 13.13$ & -7.024 \\
& Post-administration & $161.33 \pm 7.06$ & 0.302 \\
\hline
\end{tabular}

Data were analyzed using student dependent $T$ test and data were considered significant at $p<0.05$. ${ }^{*} p<0.05$ means significant. SEM means standard error of the mean. MEPO means methanolic extract of Portulaca oleracea

\section{Histopathology \\ Ovarian histology}

Plate I (group A) served as the control group and represents the histological section of the ovary of rat administered only distilled water throughout the experiment. The micrograph shows a normal ovary with follicles (F) at varying stages of development, blood vessels (BV) and corpora lutea (CL) (indicating ovulation). The staining was done using hematoxylin and eosin and photomicrography was taken at $\times 100$. Plate II (group B) shows the histological section of the ovary of rat administered $400 \mathrm{mg} / \mathrm{kg}$ MEPO for 14 days. The section shows characteristic congested blood vessels (CBV), follicles (F) at varying stages of development, and the corpora Lutea (CL). The staining was done with hematoxylin and eosin and photomicrography was taken at $\times 200$. Plate III (group C) shows the histological section of the ovary of rat administered $800 \mathrm{mg} / \mathrm{kg}$ of MEPO for 14 days showing corpora Lutea (CL), vesicular congestion (VC), and follicles (F) at varying stages of development. Staining was also done with hematoxylin and eosin while photomicrography was taken at $\times 100$.

\section{Uterine histology}

Plate IV served as the control group (group A). It represents the uterus of a rat administered only distilled water for 14 days. The section shows the uterine glands (shown with arrows), myometrium (M), endometrium (E), the lumen of the uterus (L), and blood vessels. No abnormalities were seen. The section was stained with hematoxylin and eosin and photomicrography was done at $\times 100$. Plate $V$ (group B) represents the histological section of the uterus of rat administered $400 \mathrm{mg} / \mathrm{kg}$ of MEPO. The section shows normal uterine histology with indicative uterine glands (shown with arrows), endometrium (E), the lumen (L), and blood vessels. Staining was done with hematoxylin and eosin and photomicrography was done at $\times 200$. Plate VI (group C) represents the histological section of the uterus of rat administered 800 $\mathrm{mg} / \mathrm{kg}$ of MEPO. Section show secreting uterine glands

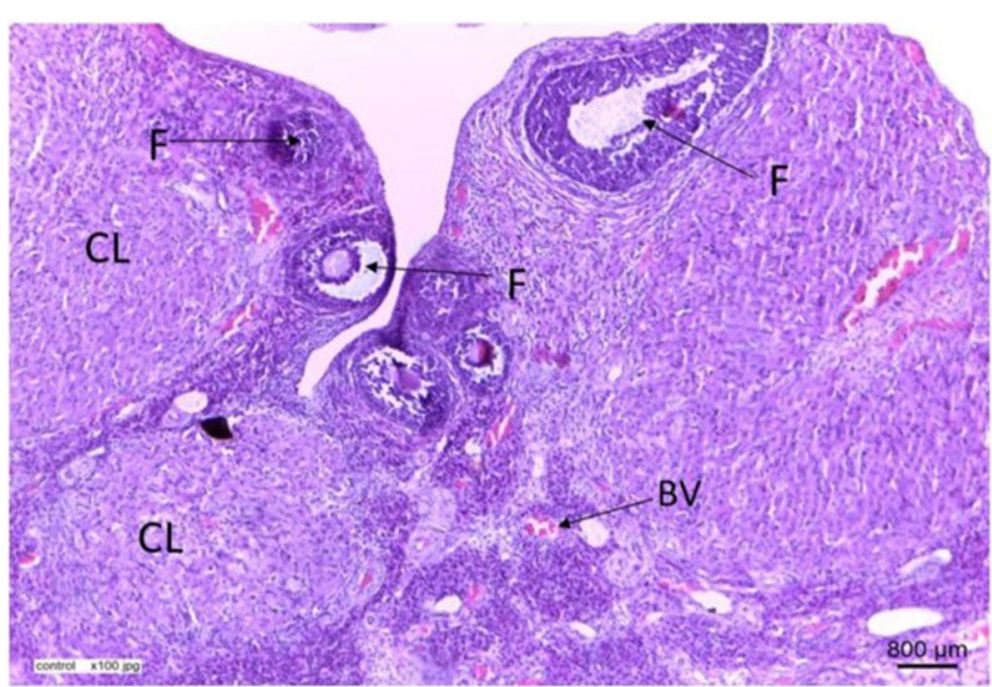

Plate I (Group A, control): Histological section of ovarian tissue of rats administered only distilled water for 14 days. Stained by H\&E $(\times 100)$. The micrograph shows a normal ovary with follicles (F) at varying stages of development, blood vessels (BV), and Corpora Lutea (CL) (indicating ovulation) 


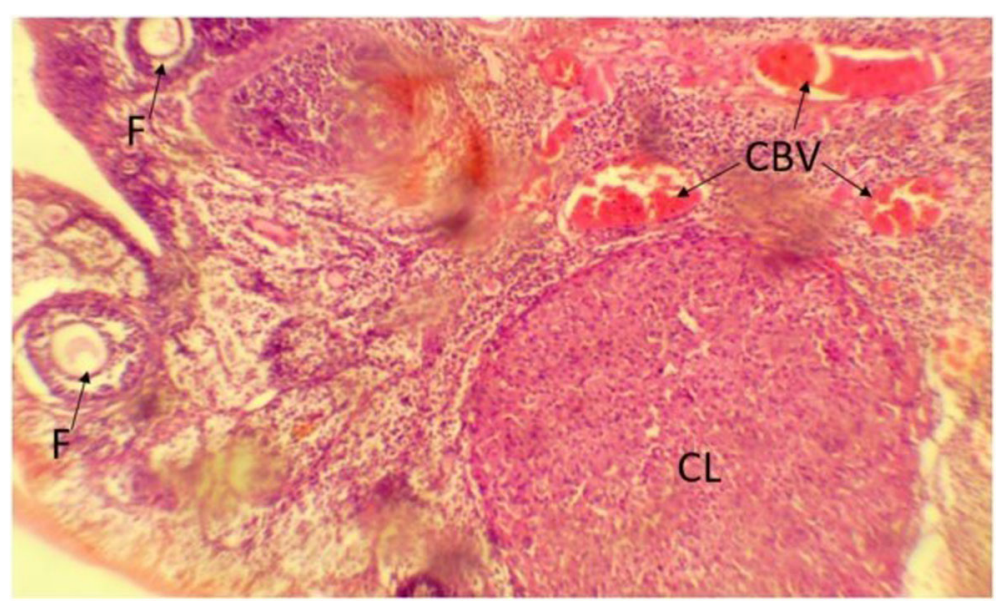

Plate II (Group B): Histological section of ovarian tissue of rat administered $400 \mathrm{mg} / \mathrm{kg}$ of methanolic extract of Portulaca oleracea for 14 days. Stained by H\&E $(\times 200)$. The section shows characteristic congested blood vessels (CBV), follicles (F) at varying stages of development, and the corpora Lutea (CL)

(indicated with arrows), endometrium (E), the lumen of the uterus (L), and few congested blood vessels (circled area). The section was stained by hematoxylin and eosin and photomicrography was done at $\times 200$.

\section{Discussion}

Findings from this study showed an insignificant $(p=$ 0.155) increase in the body weight when the preadministration weight was compared to the postadministration weight in group A. Group B had a significant $(p=0.002)$ increase when the preadministration weight was compared to the postadministration weight. Group $C$ had an insignificant ( $p=$ 0.302 ) increase when the pre-administration weight was compared to the post-administration weight. This agrees with the works of Oyedeji and Bolarinwa [16] who reported a non-significant difference in body weight of animals treated with both aqueous and methanolic extracts of Portulaca oleracea (MEPO). It however does not align with the findings of Ramadan et al. [27] who reported a significant decrease in body weight following administration of a dosage of $250 \mathrm{mg} / \mathrm{kg}$ of Portulaca Oleracea (PO). This disagreement could be a result of the longer duration observed in that study.

Organ-body weight measurements have been used to determine toxicity levels in tissues [28]. From the result observed, the non-significant change in the relative weights of ovaries of rats treated with $400 \mathrm{mg} / \mathrm{kg}$ of MEPO compared to the control could indicate normalcy in the activity of the stroma, the follicle, and the corpus luteum of the ovary. This may suggest the level of toxicity of $\mathrm{PO}$, at least at acute ingestion of the smaller

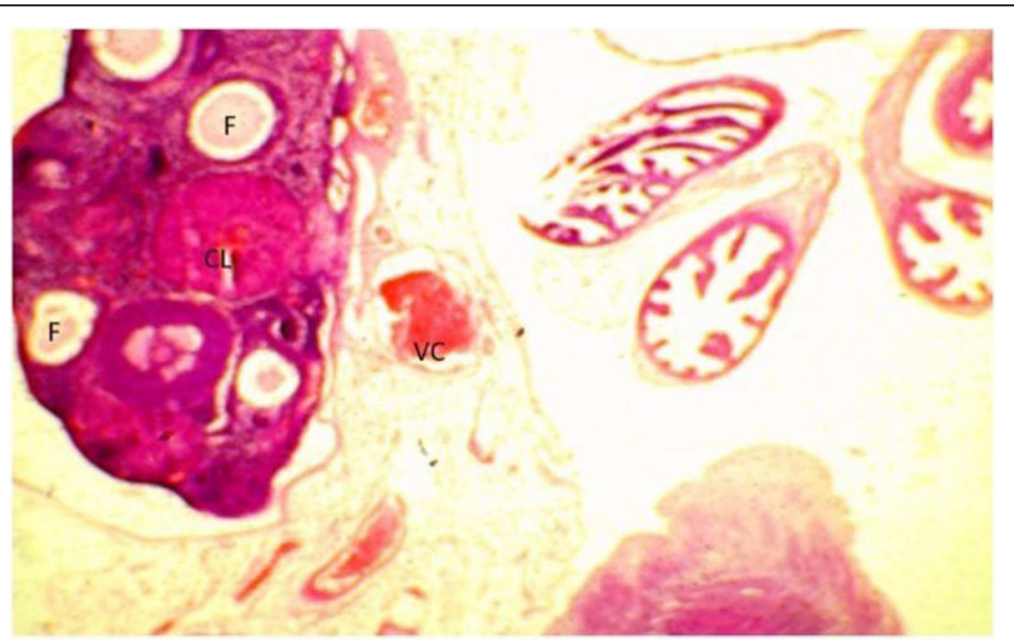

Plate III (Group C): Histological section of ovarian tissue of rat administered $800 \mathrm{mg} / \mathrm{kg}$ of methanolic extract of Portulaca oleracea for 14 days. Stained by H\&E (X100). The section shows corpora Lutea $(C L)$, vesicular congestion $(V C)$, and follicles $(F)$ at varying stages of development 


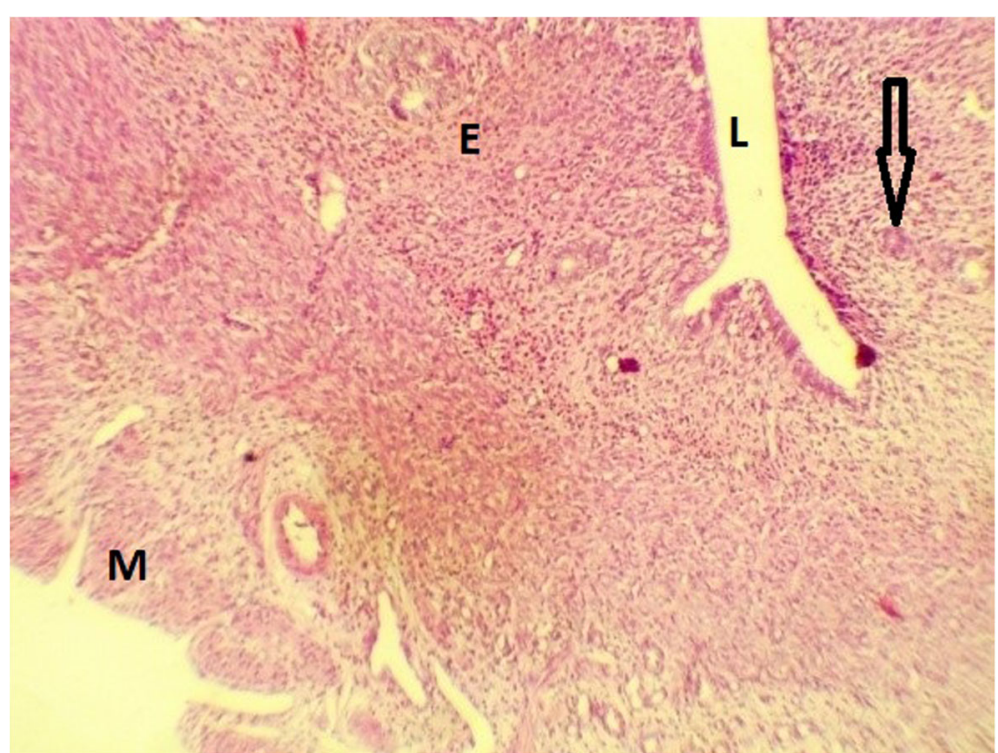

Plate IV (Group A, control): Histological section of the uterus of rat administered only distilled water for 14 days. Stained by H\&E ( $\times 100)$. The section shows the uterine glands (shown with arrows), myometrium (M), endometrium (E), the lumen of the uterus (L), and blood vessels. No abnormalities were seen

dose. Our findings on the relative ovarian weight confirm the study by Oyedeji and Bolarinwa [16] who also reported an insignificant difference in the ovarian weight following $75 \mathrm{mg} / \mathrm{kg}$ administration of MEPO. Howbeit, at a higher dose of MEPO, there was a significant decrease in relative ovarian weight $(p=0.000)$ (Table 2). As postulated, organ weight radio is a useful marker of cellular swelling, atrophy, or hypertrophy; reduction in organ weight is usually due to constriction of cells in the organ $[29,30]$. Additionally, there was a decrease in the relative uterine weight of rats treated with a higher dose of MEPO when compared to control $(p=0.037)$. Our study findings underpin the report of Oyedeji and Bolarinwa [16] who posited an insignificant decrease in the uterine weight following administration of aqueous and methanolic extracts of Portulaca oleracea. This study

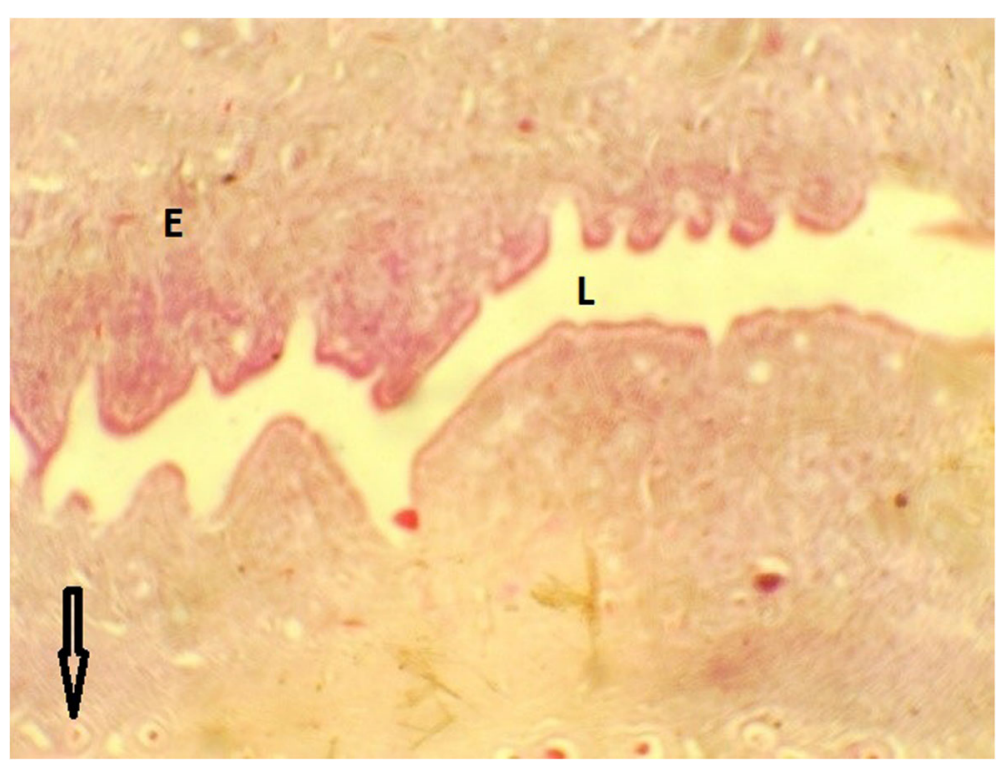

Plate $\mathbf{V}$ (Group B): Histological section of the uterus of rat administered $400 \mathrm{mg} / \mathrm{kg}$ of methanolic extract of Portulaca oleracea for 14 days. Stained by H\&E $(\times 200)$. The section shows normal uterine histology with indicative uterine glands (shown with arrows), endometrium (E), the lumen $(L)$, and blood vessels 


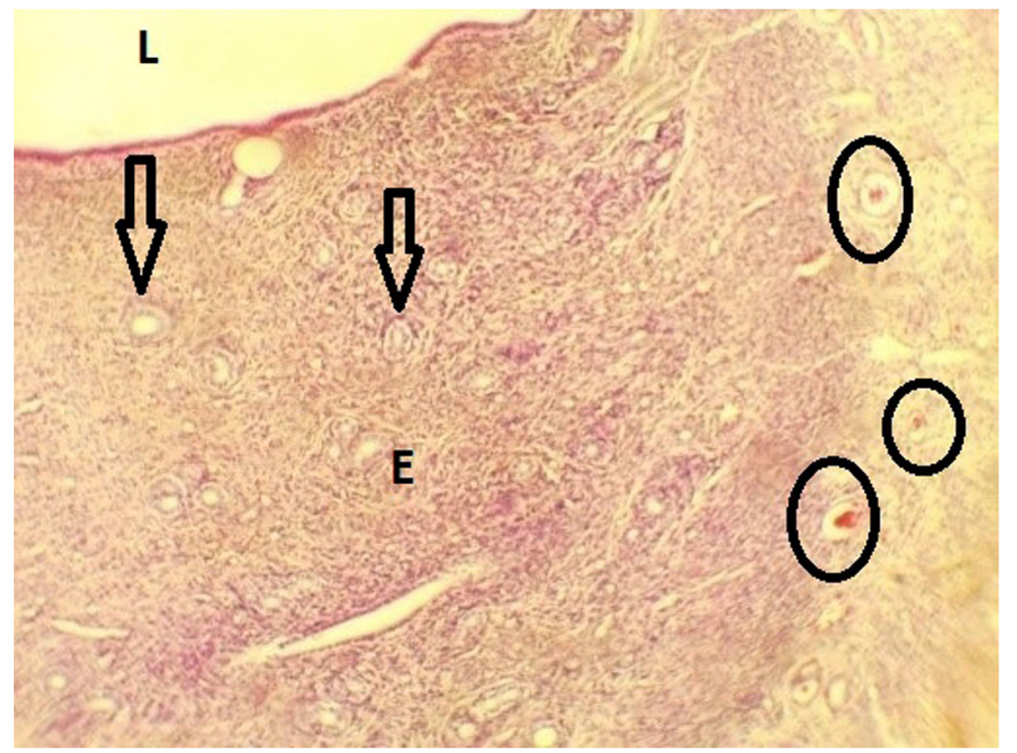

Plate VI (Group C): Histological section of the uterus of rat administered $800 \mathrm{mg} / \mathrm{kg}$ methanolic extract of Portulaca oleracea for 14 days. Stained by H\&E ( $\times 200)$. Section show secreting uterine glands (indicated with arrows), endometrium $(E)$, the lumen of the uterus $(L)$, and few congested blood vessels (circled area)

disagrees with the findings of Londonkar and Nayaka [31] and Nayaka et al. [32] whose report showed a significant increase in the weight of the uterus at high dose when compared to control and also Ahangarpour et al. [10] who reported a non-significant decrease in the uterus weight.

The hormonal levels (LH, FSH, PG, and E2) of the study groups were determined in this study. However, there was no significant change in the serum levels of any of these hormones when compared to the control group (Table 3). FSH is responsible for menstrual cycle regulation, estradiol production, and ovary stimulation for egg production. Abnormal changes of FSH could be indicative of ovarian disease or toxicity such as diminished ovarian reserves, ovarian cancer, or polycystic

Table 2 The effect of MEPO on the relative organ weight of adult female Wistar rats

\begin{tabular}{lllll}
\hline Groups & & Mean \pm SEM & $\boldsymbol{p}$ value & $\boldsymbol{F}$ value \\
\hline Relative ovarian weight & A & $0.099 \pm 0.006$ & & \\
& B & $0.076 \pm 0.012$ & 0.091 & 23.383 \\
& C & $0.014 \pm 0.005$ & $0.000^{*}$ & \\
Relative uterine weight & A & $0.20 \pm 0.02$ & & \\
& B & $0.19 \pm 0.04$ & 0.0835 & 4.222 \\
& C & $0.09 \pm 0.02$ & $0.037^{*}$ &
\end{tabular}

Data were analyzed using one-way ANOVA and were considered significant at $p<0.05 .{ }^{*} p<0.05$ means significant and $p>0.05$ means not significant. SEM means standard error of the mean. MEPO means methanolic extract of Portulaca oleracea ovarian syndrome. On macroscopic examination of the ovarian tissues excised for this study, there were no features suggestive of a diseased ovary. The observation on the FSH levels could explain the similar levels of E2 observed in the MEPO-treated groups (Table 3). High serum E2 levels are also reported to be associated with ovarian tumors while low serum E2 levels signify ovarian failure or menopause [33]. The hormonal profile observed by this study is comparable to the findings of Hosseini et al. [34] who showed that hydroalcoholic (70\%) extract $(200 \mathrm{mg} / \mathrm{kg})$ of Purslane had no significant effect on LH, FSH, estradiol, and progesterone levels in the serum of normal mice. Also, Ahangarpour et al. [10] had a similar result when testing with ethanolic extract $200 \mathrm{mg} / \mathrm{kg}$ of Purslane.

PO is a high source of omega-3 fatty acid that has been long used for medicinal purposes. Previous studies have stated that omega- 3 fatty acid tends to positively affect the ovary by increasing the number of follicles present during folliculogenesis, which may play a role in increasing fertility [35]. According to Oyedeji and Bolarinwa [16], PO can efficiently remove water bisphenol A (BPA), which is well known as an endocrine-disrupting compound (EDC) having estrogenic properties [16].

In this study, the observation of the estrous cycle before and after MEPO treatment showed a dysregulated cycle with signs of cycle arrest especially at the metestrus phase in both MEPO-treated groups. The vaginal smear micrography showed an unchanging cell distribution for the period observed (result not shown). This 
Table 3 The effect of MEPO on serum FSH, LH, progesterone, and estradiol levels of adult female Wistar rats

\begin{tabular}{|c|c|c|c|c|}
\hline Hormones groups & & Mean \pm SEM & $p$ value & $F$ value \\
\hline \multirow[t]{3}{*}{ Follicle-stimulating hormone $(\mu \mathrm{lu} / \mathrm{ml})$} & A & $1.20 \pm 0.40$ & & 0.979 \\
\hline & B & $1.54 \pm 0.23$ & 0.506 & \\
\hline & C & $1.91 \pm 0.31$ & 0.537 & \\
\hline \multirow[t]{3}{*}{ Luteinizing hormone (IU/L) } & A & $2.17 \pm 0.06$ & & 1.227 \\
\hline & B & $1.90 \pm 0.05$ & 0.367 & \\
\hline & C & $1.76 \pm 0.25$ & 0.163 & \\
\hline \multirow[t]{3}{*}{ Progesterone (ng/ml) } & A & $3.23 \pm 0.31$ & & 0.227 \\
\hline & B & $3.53 \pm 0.63$ & 0.759 & \\
\hline & C & $3.82 \pm 0.72$ & 0.523 & \\
\hline \multirow[t]{3}{*}{ Estradiol (pg/ml) } & A & $11.40 \pm 1.80$ & & 0.460 \\
\hline & B & $9.76 \pm 0.14$ & 0.372 & \\
\hline & C & $10.72 \pm 0.96$ & 0.686 & \\
\hline
\end{tabular}

Data were analyzed using one-way ANOVA, followed by multiple comparisons using LSD, and data were considered significant at $p<0.05$. ${ }^{*} p<0.05$ means significant and $p>0.05$ means insignificant. SEM means standard error of the mean. MEPO means methanolic extract of Portulaca oleracea

cycle arrest could not be explained from our study findings as the changes seen could not be deciphered through the hormonal profile. MEPO treatment at the given doses could have caused some tissue-based cellular interaction. This can only be substantiated with further biochemical and cytology studies (Table 4).

The ovarian histological assessment showed a normal ovarian architecture across all the MEPO-treated groups, but also not without vesicular congestion (Plates II and III) which is one of the cardinal indications of inflammation. However, no pathologic changes were found in the ovary which suggests the non-toxic effects of MEPO on the ovaries. Histological findings from the uterus suggest no damage of the uterus at $400 \mathrm{mg} / \mathrm{kg}$ of MEPO, and mild congestion of few blood vessels in the uterus at 800 $\mathrm{mg} / \mathrm{kg}$ of MEPO when compared with the control group (Plates IV and VI). This study agrees with the findings of

Table 4 The effect of MEPO on the estrous cycle of adult female Wistar rats

\begin{tabular}{|c|c|c|c|c|c|c|c|c|c|c|c|c|c|}
\hline \multicolumn{2}{|c|}{ Groups } & \multicolumn{4}{|l|}{ R1 } & \multicolumn{4}{|l|}{$\mathrm{R} 2$} & \multicolumn{4}{|l|}{ R3 } \\
\hline & & D1 & $\mathrm{D} 2$ & D3 & D4 & D1 & $\mathrm{D} 2$ & D3 & D4 & D1 & D2 & D3 & D4 \\
\hline \multirow[t]{2}{*}{ A } & Pre & $E$ & $M$ & $M$ & D & $E$ & $M$ & D & D & D & $P$ & $P$ & $E$ \\
\hline & Post & $M$ & $D$ & $P$ & $E$ & $M$ & $E$ & $E$ & $M$ & $E$ & $M$ & $P$ & $M$ \\
\hline \multirow[t]{2}{*}{ B } & Pre & $P$ & $E$ & $E$ & $M$ & D & $P$ & $E$ & $M$ & $P$ & M & $M$ & $\mathrm{D}$ \\
\hline & Post & $M$ & M & $M$ & $P$ & $M$ & $M$ & $D$ & M & $M$ & $P$ & $E$ & $P$ \\
\hline \multirow[t]{2}{*}{ C } & Pre & $E$ & $M$ & $M$ & $\mathrm{D}$ & $\mathrm{D}$ & $P$ & $E$ & $M$ & $M$ & $M$ & $M$ & $P$ \\
\hline & Post & $M$ & $M$ & $M$ & $M$ & $M$ & $M$ & $M$ & $P$ & D & $P$ & $P$ & $E$ \\
\hline
\end{tabular}

$R 1$ first Wistar rat, $R 2$ second Wistar rat, $R 3$ third Wistar rat, Pre preadministration, Post post-administration, $P$ Proestrus, $E$ estrous, $M$ Metestrus, $D$ Diestrus, D1 first day, D2 second day, D3 third day. Red color shows phases of estrous cycle arrest across different animals in the study groups. A-control group, given distilled water only; B-administered $400 \mathrm{mg} / \mathrm{kg}$ MEPO only; C-administered $800 \mathrm{mg} / \mathrm{kg}$ MEPO only
Oyedeji and Bolarinwa [16] who reported that aqueous and methanolic extracts of PO show no noticeable pathologic lesions in the uteri of the treated rats. There is a lot of mechanisms yet to be uncovered from the activities of MEPO in the female fertility apparatus-the subtle ovarian and uterine tissue effect with a dysregulation of the estrous cycle but without any significant hormonal effects. Perhaps, a chronic toxicological study would unfold more evidence.

One of the limitations of our study is the fact that the blood collection for the hormonal investigations was done at the same time point thus gave no chance for specific time-based hormone level determination and this may potentially affect the resulting outcome. More so, the fertility of the animals used in this study was only based on the normality of their estrous cycle and this also could be limiting.

Notwithstanding, in the era of unbridled use and abuse of crude herbal medicines and products made from natural herbs, there is a need for safety assessment and evaluation of edible plants and herbs as regards their effects on different body functions. Hence, this study will be useful as a preliminary lead and awareness on the effect of PO in female reproductive functions.

\section{Conclusion}

Our study shows an anti-fertility potential of PO as showcased by the arrest of the rat reproductive cycle and reproductive organ blood vessel congestion. However, the mechanisms behind these findings are not well understood as the reported activities seem not to be well substantiated by other parameters shown. Howbeit, it is safe to conclude that excluding the arrest of the reproductive cycle, and the vesicular congestions observed in 
tissue histology, MEPO does not have any deleterious effect on both ovarian and uterine histology, and also does not affect female reproductive hormones. Notwithstanding, it is advised that PO should not be taken at higher doses following the potentials of fertility disturbances observed in the study. There is a need for further study to validate these claims and to further elucidate any therapeutic or deleterious effect which PO may possess.

\section{Supplementary Information}

The online version contains supplementary material available at https://doi. org/10.1186/s43043-020-00048-x.

\section{Additional file 1.}

\section{Abbreviations}

PO: Portulaca oleracea; MEPO: Methanolic extract of Portulaca oleracea; FSH: Follicle-stimulating hormone; LH: Luteinizing hormone; IAO: Izuchukwu Azuka Okafor; USN: Uchenna Somtochukwu Nnamah; JN: Jude Nnaka

\section{Acknowledgements}

We want to thank Dr. Uzochukwu Ibe who assisted with the animal sacrifice and tissue collection and Mr. Johnson Nweke who assisted with the ELISA for hormone analysis.

\section{Authors' contributions}

IAO and USN contributed to the conception, study design, and acquisition of data. IAO and JN saw to the data analysis and interpretation. JN prepared the first draft of the manuscript, IAO revised the manuscript for important intellectual content, and all the authors approved the final draft of the manuscript.

\section{Funding}

No funding was received for this study.

\section{Availability of data and materials}

All the analyzed dataset results have been included in this study. The dataset for this study will only be provided upon a reasonable written request to the corresponding author.

\section{Ethics approval and consent to participate}

The ethical approval for this study was gotten from the Animal Research Ethics Committee of Anatomy Department, Faculty of Basic Medical Sciences, Nnamdi Azikiwe University, Nnewi Campus, Nnewi, Nigeria with ethical approval number AREC/ANA/2019/0015.

\section{Consent for publication}

Not applicable.

\section{Competing Interests}

There is no conflict of interest to declare.

\section{Author details \\ ${ }^{1}$ Department of Anatomy, Faculty of Basic Medical Sciences, College of Health Sciences, Nnamdi Azikiwe University, Nnewi Campus, PMB 5001 Nnewi, Nigeria. ${ }^{2}$ Department of Obstetrics and Gynaecology, College of Medicine, Pan African University of Life and Earth Science Institute (Including health and Agriculture) PAULESI, University of Ibadan, Ibadan, Nigeria. ${ }^{3}$ Hematology Department, Babcock University Teaching Hospital, Ilisan-Remo, Ogun State, Nigeria.}

Received: 28 February 2020 Accepted: 27 December 2020 Published online: 19 January 2021

\section{References}

1. Galhardo A, Marina C, José P (2011) Psychological Aspects in Couples with Infertility. Sexologies 20(4):224-228
2. Zegers-Hochschild F, Adamson GD, de Mouzon J, Ishihara O, Mansour R (2009) Nygren K, et al, on behalf of ICMART and WHO (2009) The International Committee for Monitoring Assisted Reproductive Technology (ICMART) and the World Health Organization (WHO) Revised Glossary on ART Terminology. Hum Reprod 24:2683-2687

3. Agarwal A, Aditi M, Alaa H, Michelle RC (2015) A unique view on male infertility around the globe. Reprod Biol Endocrinol 13(1):37

4. Poongothai J, Gopenath TS, Manonayaki S (2009) Genetics of human male infertility. Singap Med J 50(4):336-347

5. Vander BM, Wyns C (2018) Fertility and infertility: definition and epidemiology. Clin Biochem 62:2-10

6. Unuane D, Herman T, Brigitte V, Kris P (2011) Endocrine disorders \& female infertility. Best Pract Res Clin Endocrinol Metab 25(6):861-873

7. Nasri H, Shirzad H, Baradaran A, Rafieian M (2015) Antioxidant plants and diabetes mellitus. J Isfahan Univ Med Sci 20(5):491-502

8. Sharafati R, Rafieian M, Salehi E (2015) Bioactivity of Apium petroselinum and Portulaca oleracea essential oils as natural preservatives. Jundishapur J Microbiol 8(3):e20128

9. Sabeeha S, Nahida T (2018) Study of ethanolic extract of Portulaca oleracea (whole plant) on blood glucose levels and body weight in streptozotocin induced diabetic rats. Int Res J Pharmacol 9(4):71-76

10. Ahangarpour A, Lamoochi Z, Moghaddam H, Mansouri S (2016) Effects of Portulaca oleracea ethanolic extract on reproductive system of aging female mice. Int J Reprod Biomed 14(3):205-212

11. Liu L, Howe P, Zhou Y, Xu Z, Hocart C, Zhang R (2000) Fatty acids and $\beta$ carotene in Australian purslane (Portulaca oleracea) varieties. J Chromatogr A 893(1):207-213

12. Lee AS, Lee YJ, Lee SM, Yoon JJ, Kim JS, Kang DG (2012) Lee HS (2012) Portulaca oleracea Ameliorates Diabetic Vascular Inflammation and Endothelial Dysfunction in db/db Mice. Evid Based Complement Alternat Med 741824:9 https://doi.org/10.1155/2012/741824

13. UddinMK JAS, Hossain MS, Un Nahar MA, Ali ME, Rahman MM (2014, 2014) Purslane Weed (Portulaca oleracea): A Prospective Plant Source of Nutrition, Omega-3 Fatty Acid, and Antioxidant Attributes. Sci World J (951019):6 https://doi.org/10.1155/2014/951019

14. Xu X, Yu L, Chen G (2006) Determination of flavonoids in Portulaca oleracea L. by capillary electrophoresis with electrochemical detection. J Pharm Biomed Anal 41(2):493-499

15. Obinna V, Kagbo H, Agu G (2019) Effects of Lipophilic and Hydrophilic leaf extracts of Portulaca oleracea Linn. (Purslane) on male reproductive parameters in albino rats. Am J Physiol Biochem Pharmacol 9:21-32

16. Oyedeji KO, Bolarinwa AF (2010) Effect of extracts of Portulaca oleracea L. on reproductive functions in male albino rats. Afr J Biomed Res 15:41-47

17. Okafor IA, Ayalokunrin MB, Orachu LA (2014) A review on Portulaca oleracea (purslane) plant-its nature and biomedical benefits. Int J Biomed Res 5(2): $75-80$

18. Charan J, Kantharia ND (2013) How to calculate sample size in animal studies? J Pharmacol Pharmacother 4:303-306

19. Arifin WN, Zahiruddin WM (2017) Sample size calculation in animal studies using resource equation approach. Malays J Med Sci 24(5):101-105 https:// doi.org/10.21315/mjms2017.24.5.11

20. Kilkenny C, Browne WJ, Cuthill IC, Emerson M, Altman DG (2010) Improving bioscience research reporting: the ARRIVE guidelines for reporting animal research. PLoS Biol 8(6):e1000412 https://doi.org/10.1371/journal.pbio. 1000412

21. Guillen JJ (2012) FELASA guidelines and recommendations. Am Assoc Lab Anim Sci 51(3):311-321

22. Long JA, Evans HM (1922) The estrous cycle in the rat and its associated phenomena. Memories Univ Calif 6:1-148

23. Mandl AM (1951) The phases of the estrous cycle in the adult white rat. J Exp Biol 28:576-584

24. McLean AC, Valenzuela N, Fai S, Bennet SA (2012) Performing vaginal lavage, crystal violet staining, and vaginal cytological evaluation or mouse estrous cycle staging identification. J Vis Exp 15(67):e4389

25. Accubind (2016) AccuBind enzyme-linked immunoabsorbent assay (ELISA) procedure. Lake forest, Monobind Inc Accessed 15 Aug 2016

26. Rowley JE, Rubenstein GE, Manuel SL, Johnson NL, Surgnier J, Kapitsinou PP Duncan FE, Pritchard MT (2020) Tissue-specific fixation methods are required for optimal in situ visualization of hyaluronan in the ovary, kidney, and liver. J Histochem Cytochem 68(1):75-91 https://doi.org/10.1369/ 0022155419884879 
27. Ramadan BK, Schaalan MF, Tolba AM (2017) Hypoglycemic and pancreatic protective effects of Portulaca oleracea extract in alloxan induced diabetic rats. BMC Complement Altern Med 17:37 https://doi.org/10.1186/s12906016-1530-1

28. Sellers RS, Daniel M, Bindhu M, Nigel R, Julie KJ, Barry LY, Rick P, Ken S (2007) Society of toxicologic pathology position paper: organ weight recommendations for toxicology studies. Toxicol Pathol 35(5):751-755

29. Akanji MA, Amadu KS, Yakubu MT (2013) Safety evaluation of aqueous extract of Crateva adansonii leaves on selected tissues of rats. Fount J Nat Appl Sci 2(1):17-28

30. Amresh G, Paras NS, Chandana VR (2008) Toxicological screening of traditional medicine laghupatha (Cissampelos Pareira) in experimental animals. J Ethnopharmacol 116(3):454-460

31. Londonkar RL, Nayaka HB (2013) Effect of ethanol extract of Portulaca oleracea $L$ on ovulation and estrous cycle in female albino rats. J Pharm Res 6:431-436

32. Nayaka HB, Londonkar RL, Andumesh MK (2014) Evaluation of Portulaca oleracea for anti-fertility effect in female albino Rats. Int J Pharm Pharm Sci 6:86-89

33. Cole L (2010) Biological functions of hCG and hCG-related molecules. Reprod Biol Endocrinol 8(102):75

34. Hosseini E, Frozanfar M, Payehdar A (2013) The effect of hydroalcoholic extract of purslane on serum concentration of estrogen, progesterone, prolactin and gonadotropins in mature female rats. J Shahrekord Univ Med Sci 15:12-21

35. Nehra D, Hau DL, Erica MF, Sarah JC, Dori W, Yvonne AW, Amy HP, Lankai G, Scott JR, Jonathan LT, Bo RR, Mark P (2012) Prolonging the female reproductive lifespan and improving egg quality with dietary omega-3 fatty acids. Aging Cell 11(6):1046-1054

\section{Publisher's Note}

Springer Nature remains neutral with regard to jurisdictional claims in published maps and institutional affiliations.

\section{Submit your manuscript to a SpringerOpen ${ }^{\circ}$ journal and benefit from:}

- Convenient online submission

- Rigorous peer review

- Open access: articles freely available online

- High visibility within the field

- Retaining the copyright to your article

Submit your next manuscript at $\boldsymbol{\nabla}$ springeropen.com 